\title{
Platelet Indices as Predictive Markers of Prognosis in Pediatric Septic Shock Patients
}

\author{
Seung Jun Choi, ${ }^{1}$ Eun-Ju Ha, ${ }^{1}$ Won Kyoung Jhang, ${ }^{1}$ and Seong Jong Park ${ }^{1,}{ }^{,}$ \\ ${ }^{1}$ Division of Pediatric Critical Care Medicine, Department of Pediatrics, Asan Medical Center Children's Hospital, University of Ulsan College of Medicine, Seoul, Republic of \\ Korea \\ "Corresponding author: Dr. Seong Jong Park, Division of Pediatric Critical Care Medicine, Department of Pediatrics, Asan Medical Center Children's Hospital, University of \\ Ulsan College of Medicine, 388-1 Pungnap-2 dong, Songpa-gu, Seoul 138-736, Republic of Korea. Tel: +82-230103390, Fax: +82-230103725, E-mail: goodjobman79@naver.com \\ Received 2016 May 22; Revised 2017 February 09; Accepted 2017 March 19.
}

\begin{abstract}
Background: Platelet indices are used as predictive marker of mortality in adult critically ill patients.

Objectives: To compare platelet counts, mean platelet volumes (MPV), and platelet distribution widths (PDW) in surviving and nonsurviving pediatric septic shock patients and to assess whether platelet count and indices can be utilized as predictive markers of mortality in these patients.

Methods: A retrospective study was performed based on collected data on pediatric patients admitted for septic shock to pediatric intensive care unit. Complete blood cell count, platelet counts, MPV, and PDW on admission were compared in survivors and nonsurvivors, as well as in patients with and without underlying hemato-oncologic disease.

Results: Of 83 children, 21 (25.3\%) died within 28 days of hospital admission. Mean platelet count was significantly higher in the 62 survivors than in 21 non-survivors $\left(146.6 \pm 133.7 \times 10^{3} / \mathrm{mm}^{3}\right.$ vs $\left.46.1 \pm 44.1 \times 10^{3} / \mathrm{mm}^{3}, \mathrm{P}=0.000\right)$. MPV and PDW were also higher in survivors, though not statistically significant $(\mathrm{P}=0.059, \mathrm{P}=0.077)$. The platelet counts were significantly higher in survivors than in non-survivors with $(\mathrm{P}=0.044)$ and without $(\mathrm{P}=0.015)$ hemato-oncologic disease. Based on area under receiver operating characteristic curves, platelet count was the strongest predictor of mortality in pediatric patients without underlying hemato-oncologic disease (area under the curve $=0.857$ ). The survival probability in this group was $96.77 \%$ when platelet count exceeded $106.5 \times$ $10^{3} / \mathrm{mm}^{3}$.

Conclusions: Thrombocytopenia is a useful predictive marker of mortality in pediatric septic shock patients, both with and without underlying hemato-oncologic disease.
\end{abstract}

Keywords: Septic Shock, Pediatrics, Platelet Indices, Pediatric Intensive Care Unit, Mortality

\section{Background}

Thrombocytopenia is frequently encountered in patients admitted to intensive care units (ICUs), and has been shown to be predictive of mortality in adult patients (14 ), as well as in pediatric patients admitted to pediatric ICUs (PICUs) (5). Thrombocytopenia in sepsis patients is caused by combinations of several mechanisms, including decreased platelet synthesis, increased platelet destruction, and thrombus formation (6), with approximately $40 \%$ of patients with severe sepsis having platelet counts below $80,000 / \mathrm{mm}^{3}$ (7). During episodes of septic shock, platelets aggregate around the site of inflammation, with subsequent multiorgan failure aggravating thrombocytopenia (8).

Several studies have shown that platelet counts and function are reduced in patients with severe sepsis and septic shock (9-11). Moreover, platelet indices, such as mean platelet volume (MPV) and platelet distribution width (PDW), have been associated with these conditions $(12,13)$. Increased MPV was observed in adults with septic shock
(14) and in neonatal sepsis patients (15). Less is known, however, about platelet counts and platelet indices in pediatric sepsis patients.

This study was designed to evaluate the association of platelet counts and platelet indices with mortality in pediatric septic shock patients, as well as to assess whether platelet parameters are predictive markers of survival in these patients. Because the presence of underlying hemato-oncologic disease may greatly influence baseline platelet counts, the associations between platelet parameters and mortality were separately analyzed in groups of patients with and without underlying hemato-oncologic disease.

\section{Methods}

The medical records of pediatric patients admitted to the PICU of Asan medical center children's hospital, Seoul, Korea, from February 2012 through May 2015, with a diagnosis of septic shock, were retrospectively reviewed. Septic 
shock was defined according to the 2005 international pediatric sepsis consensus conference (IPSCC) criteria (16).

The demographic characteristics, underlying diseases, sources of infection, and laboratory results of all included patients were obtained from their medical records. The severity of illness and organ dysfunction were assessed by measuring Pediatric Risk of Mortality III (PRISM III) scores, sequential organ failure assessment (SOFA) scores, and Vasoactive Inotropic Scores (VIS) within 24 hrs of PICU admission.

Complete blood cell (CBC) count and blood chemistry were measured within 1 hour of admission to the PICU. Platelet count, MPV, and PDW were obtained from routine $\mathrm{CBC}$ results. All statistical analyses were performed using Windows SPSS software, version 18. Continuous variables in survivors and non-survivors were compared using independent t-tests. Receiver operating characteristic (ROC) curve analyses were performed to evaluate the usefulness of platelet parameters as prognostic markers. For each variable, 95\% confidential intervals (CIs) and optimal cutoff points were determined. A P value less than 0.05 was considered statistically significant.

The study protocol was approved by the institutional review board of the Asan Medical Center.

\section{Results}

A total of 90 pediatric patients were admitted to the PICU for septic shock from February 2012 to May 2015. Seven patients were excluded owing to a lack of relevant data at admission, including MPV and PDW; thus, 83 patients were enrolled. The 28 day in-hospital mortality rate was $25.3 \%$ (21/83). Of the 83 patients, 78 (94.0\%) had underlying diseases, with 38 having hemato-oncologic diseases. Pathogenic microorganisms were documented in 47 patients. The most common Gram-positive and Gramnegative bacteria were Staphylococcus aureus and Klebsiella pneumoniae, respectively, and all cases of fungal sepsis were attributed to Candida albicans (Table 1).

Age, sex, and length of PICU stay did not differ significantly in survivors and non-survivors. PRISM III, SOFA, and VIS scores, all of which reflect disease severity, were significantly greater in the non-survivors than in survivors. Documentation of pathogen was not associated with survival, but underlying disease was. Of the 21 nonsurvivors, 14 (66.7\%) had underlying hemato-oncologic disease. C-reactive protein (CRP) and lactate concentrations were significantly higher in non-survivors than in survivors. Platelet count was 3-fold higher in survivors than in non-survivors $\left(146.6 \pm 133.7 \times 10^{3} / \mathrm{mm}^{3}\right.$ vs $46.1 \pm 44.1 \times$ $\left.10^{3} / \mathrm{mm}^{3}, \mathrm{P}=0.000\right)$. Mean MPV $(\mathrm{P}=0.059)$ and PDW $(\mathrm{P}=$
Table 1. Patient Characteristics ${ }^{\mathrm{a}}$

\begin{tabular}{|c|c|}
\hline Variables & No. of Patients \\
\hline $\mathbf{N}$ & 83 \\
\hline Age, months & $128.0 \pm 159.6$ \\
\hline Gender, male/female & $52 / 31$ \\
\hline Mortality & $21(25.3)$ \\
\hline Underlying disease & $78(94.0)$ \\
\hline Hemato-oncologic disease & $38(48.7)$ \\
\hline Neurologic disease & $13(16.7)$ \\
\hline Cardiac disease & $8(10.3)$ \\
\hline Pulmonary disease & $6(7.7)$ \\
\hline Chronic renal disease & $5(6.4)$ \\
\hline Gastrointestinal disease & $3(3.8)$ \\
\hline Endocrinologic disease & $3(3.8)$ \\
\hline Other & $2(2.6)$ \\
\hline Proven microorganism & $47(56.6)$ \\
\hline Gram-positive bacteria & $19(40.4)$ \\
\hline Staphylococcus aureus & 5 \\
\hline Streptococcus mitis & 3 \\
\hline Streptococcus agalactiae & 2 \\
\hline Staphylococcus hominis & 2 \\
\hline Enterococcus faecalis & 2 \\
\hline Other & 5 \\
\hline Gram-negative bacteria & $22(46.8)$ \\
\hline Klebsiella pneumonia & 9 \\
\hline Escherichia coli & 5 \\
\hline Pseudomonas aeruginosa & 4 \\
\hline Enterobacter cloacae & 2 \\
\hline Other & 2 \\
\hline Fungus & $6(12.8)$ \\
\hline Candida albicans & 6 \\
\hline
\end{tabular}

${ }^{\mathrm{a}}$ Values are expressed as mean \pm SD or No. (\%).

0.077) were higher in survivors, but the differences were not statistically significant (Table 2).

The associations between platelet count and mortality according to underlying disease were analyzed separately in the 38 patients with and the 45 without hematooncologic disease. Mean platelet counts in both subgroups were significantly higher in survivors than in nonsurvivors (Table 3). ROC analysis showed that the areas under the curve (AUCs) were 0.796 for all patients, 0.722 for patients with hemato-oncologic diseases, and 0.857 for pa- 
Table 2. Clinical Characteristics of Survivors and Non-Survivors ${ }^{\mathrm{a}}$

\begin{tabular}{|c|c|c|c|c|}
\hline Variables & All Patients $(n=83)$ & Survivors $(n=62)$ & Non-Survivors $(\mathbf{n}=\mathbf{2 1})$ & P Value \\
\hline Age, mo & $128.0 \pm 159.6$ & $114.4 \pm 85.0$ & $168.3 \pm 282.9$ & 0.182 \\
\hline Male & $52(62.7)$ & $38(61.3)$ & $14(66.7)$ & 0.796 \\
\hline Length of PICU stay & $14.84 \pm 15.30$ & $14.77 \pm 15.82$ & $15.05 \pm 14.00$ & 0.944 \\
\hline PRISM III score & $15.67 \pm 8.17$ & $13.55 \pm 5.67$ & $21.95 \pm 10.95$ & 0.003 \\
\hline SOFA score & $9.71 \pm 3.17$ & $8.87 \pm 2.72$ & $12.19 \pm 3.16$ & 0.000 \\
\hline VIS & $35.00 \pm 38.46$ & $27.66 \pm 25.19$ & $56.68 \pm 58.88$ & 0.039 \\
\hline Hemato-oncologic disease & $38(45.8)$ & $24(38.7)$ & $14(66.7)$ & 0.042 \\
\hline Proven microorganism & $47(56.6)$ & $35(56.5)$ & $12(57.1)$ & 0.956 \\
\hline \multicolumn{5}{|l|}{ Laboratory findings } \\
\hline $\mathrm{WBC}, \mathrm{mm}^{3}$ & $6,567 \pm 7,468$ & $7,223 \pm 7,487$ & $4,633 \pm 7,243$ & 0.171 \\
\hline Platelet, $\times 10^{3} / \mathrm{mm}^{3}$ & $121.1 \pm 125.3$ & $146.6 \pm 133.7$ & $46.1 \pm 44.1$ & 0.000 \\
\hline Mean platelet volume, fl & $10.50 \pm 1.12$ & $10.63 \pm 1.18$ & $10.10 \pm 0.80$ & 0.059 \\
\hline Platelet distribution width, fl & $12.17 \pm 2.81$ & $12.48 \pm 2.98$ & $11.23 \pm 2.05$ & 0.077 \\
\hline $\mathrm{CRP}, \mathrm{mg} / \mathrm{dL}$ & $15.03 \pm 9.41$ & $13.85 \pm 8.85$ & $18.52 \pm 10.33$ & 0.049 \\
\hline Lactate, $\mathrm{mmol} / \mathrm{L}$ & $3.88 \pm 4.06$ & $2.45 \pm 2.21$ & $8.10 \pm 5.25$ & 0.000 \\
\hline
\end{tabular}

Abbreviations: CRP, C-reactive protein; PICU, pediatric intensive care unit; PRISM III, pediatric risk of mortality III; SOFA, sequential organ failure assessment; VIS, vasoactive inotropic scores; WBC, white blood cell.

${ }^{\mathrm{a}}$ Values are expressed as mean \pm SD or No. (\%)

tients without hemato-oncologic diseases (Figure 1). Using Youden's J-statistics, we calculated that the platelet count cutoffs for predicting mortality were $52.0 \times 10^{3} / \mathrm{mm}^{3}$ for all patients, $30.5 \times 10^{3} / \mathrm{mm}^{3}$ for patients with hematooncologic diseases, and $106.5 \times 10^{3} / \mathrm{mm}^{3}$ for patients without hemato-oncologic diseases, with sensitivities of $71.4 \%$, $78.6 \%$, and $85.7 \%$, respectively, and specificities of $71.0 \%$, $66.7 \%$, and $78.9 \%$, respectively. The accuracies, positive predictive values, and negative predictive values for these cutoffs are shown in Table 4. The risk ratios for mortality in these three groups of patients with platelet counts under the cutoff values were 6.111, 7.333, and 22.5, respectively (Table 4). With the significant variable from the univariate analysis, a multivariate logistic regression analysis was executed, and the platelet count was statistically significant $(\mathrm{OR}=0.988, \mathrm{P}=0.04$, Table 5).

\section{Discussion}

Thrombocytopenia is frequently encountered in severe sepsis patients (9) and has been associated with prognosis $(17,18)$. However the association between platelet indices and mortality in septic shock patients is unclear. For example, increased MPV has been associated with mortality in adult septic shock patients $(19,20)$, but has shown contradictory results in neonatal patients with sep-
Table 3. Mean Platelet Counts in Survivors and Non-Survivors

\begin{tabular}{lccc}
\hline $\begin{array}{l}\text { Platelet, } \times \\
\mathbf{1 0}^{\mathbf{3}} / \mathbf{m m}^{\mathbf{3}}\end{array}$ & Survivors $(\mathbf{n}=\mathbf{6 2})$ & $\begin{array}{c}\text { Non-Survivors }(\mathbf{n} \\
\mathbf{2 1})\end{array}$ & P Value \\
\hline All patients & $146.6 \pm 133.7$ & $46.1 \pm 44.1$ & 0.000 \\
$\begin{array}{l}\text { With hemato- } \\
\text { oncologic } \\
\text { diseases }\end{array}$ & $43.1 \pm 22.4$ & $28.6 \pm 16.9$ & 0.044 \\
$\begin{array}{l}\text { Without hemato- } \\
\text { oncologic } \\
\text { diseases }\end{array}$ & $211.9 \pm 133.6$ & $81.0 \pm 61.0$ & 0.015 \\
\hline
\end{tabular}

sis (21). Our study, involving pediatric septic shock patients, showed that platelet count on PICU admission was significantly associated with mortality, but that platelet indices such as MPV and PDW were not associated with mortality in these patients.

This study had two major findings. First, platelet count was predictive of mortality in pediatric septic shock patients, regardless of the underlying disease. Whether or not these patients had an underlying hemato-oncologic disease did not affect the association between platelet count and mortality. Low platelet counts are not uncommon in patients with hemato-oncologic diseases, even during disease-free periods, due both to the underlying disease itself and to treatment methods such as 


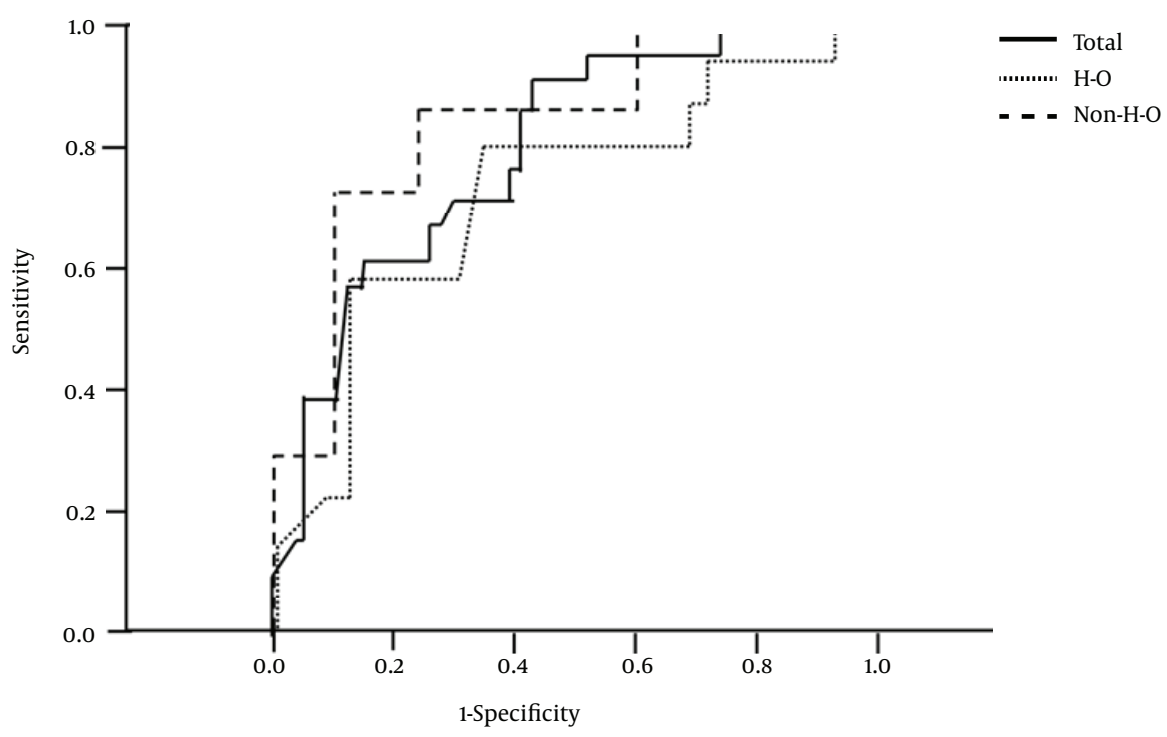

\begin{tabular}{lccc}
\hline \multicolumn{1}{c}{ Platelet } & AUC & P - value & 95\% CI \\
\hline All patient & 0.796 & 0.000 & $0.692-0.900$ \\
With hemato-oncologic diseases & 0.722 & 0.024 & $0.546-0.898$ \\
Without hemato-oncologic diseases & 0.857 & 0.003 & $0.700-1.000$ \\
\hline
\end{tabular}

Abbreviations: H-O, hema to-oncologic diseases

Figure 1. Receiver Operating Characteristic (ROC) Curve Analysis of the Associations Between Platelet Counts and Mortality

chemotherapy and irradiation. We found, however, that the mean platelet count in surviving patients with hematooncologic diseases was $43.1 \times 10^{3} / \mathrm{mm}^{3}$, which, although lower than the normal reference range, and even lower than minimum criteria $\left(50.0 \times 10^{3} / \mathrm{mm}^{3}\right)$ of the pediatric risk of mortality (PRISM) III score, was significantly higher than that of non-survivors with hemato-oncologic diseases. Even among patients without hemato-oncologic diseases, who had baseline platelet counts in the normal reference range, platelet count was predictive of mortality, with an AUC of 0.857 , a sensitivity of $85.7 \%$, and a specificity of $78.9 \%$.

The second major finding of this study was the determination of cutoff values for platelet count predictive of mortality, suggesting specific reference ranges that can be utilized in clinical settings. Platelet counts showed excellent negative predictive values in all patients $(88.0 \%)$ and in patients with $(84.2 \%)$ and without $(96.8 \%)$ hematooncologic diseases. Patients with platelet count higher than the cutoff values would therefore be at decreased risk of 28 day mortality. For example, the predicted surviv- ability rate in pediatric septic shock patients without underlying hemato-oncologic diseases and an initial platelet count of $106.5 \times 10^{3} / \mathrm{mm}^{3}$ is $96.8 \%$.

Additional studies are needed to determine whether platelet transfusions that maintain adequate platelet count can reduce mortality rates in pediatric septic shock patients. Platelet transfusion guidelines recommend different criteria based on the underlying disease or clinical status of the patients (22-24). We observed that a cutoff value of $30.5 \times 10^{3} / \mathrm{mm}^{3}$ had optimal sensitivity and specificity in patients with hemato-oncologic diseases. Thus, future studies may address whether platelet transfusions that maintain platelet counts above this cutoff in pediatric septic shock patients with underlying hemato-oncologic diseases can potentially enhance survival rate.

This study had several limitations. It was a retrospective observational study with a small sample size conducted in a single medical center. Further, we did assess the effects of microorganisms on platelet counts. Microorganisms have been shown to alter platelet responses in both very low birth weight infants $(25,26)$ and adults $(14)$. How- 
Table 4. Cutoff Values for Platelet Count in Patients With and Without HematoOncologic Diseases $^{\mathrm{a}}$

\begin{tabular}{lccc}
\hline $\begin{array}{l}\text { Validation } \\
\text { Values }\end{array}$ & All Patients & $\begin{array}{c}\text { With hemato- } \\
\text { Oncologic } \\
\text { Diseases }\end{array}$ & $\begin{array}{c}\text { Without } \\
\text { Hemato- } \\
\text { Oncologic } \\
\text { Diseases }\end{array}$ \\
\hline $\begin{array}{l}\text { Platelet, } \times \\
\mathbf{1 0}^{3} / \mathbf{m m}^{\mathbf{3}}\end{array}$ & 52.0 & 30.5 & 106.5 \\
\hline Sensitivity & 71.4 & 78.6 & 85.7 \\
\hline $\begin{array}{l}\text { Specificity } \\
\text { Accuracy }\end{array}$ & 71.0 & 66.7 & 78.9 \\
\hline $\begin{array}{l}\text { Positive } \\
\text { predictive value }\end{array}$ & 71.1 & 71.0 & 80.0 \\
\hline $\begin{array}{l}\text { Negative } \\
\text { predictive value }\end{array}$ & 85.5 & 57.9 & 42.9 \\
\hline Risk ratio & 6.111 & 84.2 & 96.8 \\
\hline 95\% CI & $2.046-18.251$ & $1.583-33.967$ & $2.357-214.778$ \\
\hline P Value & 0.001 & 0.017 & 0.002 \\
\hline
\end{tabular}

Abbreviation: $\mathrm{CI}$, confidence interval.

${ }^{\mathrm{a}}$ Values are expressed as \%.

Table 5. Multivariate Logistic Regression Analysis for Mortality

\begin{tabular}{lccc}
\hline Variables & Coefficient & P Value & $\begin{array}{c}\text { Odds Ratio (95\% } \\
\text { Confidence Interval) }\end{array}$ \\
\hline PRISM III & 0.092 & 0.145 & $1.096(0.969-1.240)$ \\
\hline SOFA & 0.230 & 0.062 & $1.258(0.988-1.601)$ \\
\hline VIS & -0.002 & 0.813 & $0.998(0.981-1.015)$ \\
\hline Platelet counts & -0.012 & 0.040 & $0.988(0.977-0.999)$ \\
\hline MPV & -0.694 & 0.230 & $0.500(0.161-1.551)$ \\
\hline PDW & -0.008 & 0.974 & $0.992(0.630-1.563)$ \\
\hline
\end{tabular}

Abbreviation: MPV, mean platelet volume; PDW, platelet distribution width; PRISM III, pediatric risk of mortality III; SOFA, sequential organ failure assessment; VIS, Vasoactive Inotropic Scores.

ever, microorganism growth was documented in few of these patients. Large-scale, prospective, multicenter studies that include data on microorganisms are needed to validate our findings.

In conclusion, platelet count is a useful predictor of mortality in pediatric septic shock patients, regardless of the presence of underlying hemato-oncologic disease. In contrast, MPV and PDW were not significant predictors of patient mortality.

\section{References}

1. Baughman RP, Lower EE, Flessa HC, Tollerud DJ. Thrombocytopenia in the intensive care unit. Chest. 1993;104(4):1243-7. [PubMed: 8404200].

2. Stephan F, Hollande J, Richard O, Cheffi A, Maier-Redelsperger M, Flahault A. Thrombocytopenia in a surgical ICU. Chest. 1999;115(5):136370. [PubMed: 10334154].
3. Strauss R, Wehler M, Mehler K, Kreutzer D, Koebnick C, Hahn EG. Thrombocytopenia in patients in the medical intensive care unit: bleeding prevalence, transfusion requirements, and outcome. Crit Care Med. 2002;30(8):1765-71. [PubMed: 12163790].

4. Vanderschueren S, De Weerdt A, Malbrain M, Vankersschaever D, Frans E, Wilmer A, et al. Thrombocytopenia and prognosis in intensive care. Crit Care Med. 2000;28(6):1871-6. [PubMed: 10890635].

5. Krishnan J, Morrison W, Simone S, Ackerman A. Implications of thrombocytopenia and platelet course on pediatric intensive care unit outcomes. Pediatr Crit Care Med. 2008;9(5):502-5. doi: 10.1097/PCC.ob013e3181849af1. [PubMed: 18679144].

6. Wittels EG, Siegel RD, Mazur EM. Thrombocytopenia in the Intensive Care Unit Setting. J Intens Care Med. 1990;5(5):224-40. doi: 10.1177/088506669000500507.

7. Bernard GR, Vincent JL, Laterre PF, LaRosa SP, Dhainaut JF, LopezRodriguez A, et al. Efficacy and safety of recombinant human activated protein C for severe sepsis. N Engl J Med. 2001;344(10):699-709. doi: 10.1056/NEJM200103083441001. [PubMed: 11236773].

8. Gawaz M, Fateh-Moghadam S, Pilz G, Gurland HJ, Werdan K. Platelet activation and interaction with leucocytes in patients with sepsis or multiple organ failure. Eur J Clin Invest. 1995;25(11):843-51. [PubMed: 8582450].

9. Gawaz M, Dickfeld T, Bogner C, Fateh-Moghadam S, Neumann FJ. Platelet function in septic multiple organ dysfunction syndrome. Intensive Care Med. 1997;23(4):379-85. [PubMed: 9142575].

10. Vincent JL, Yagushi A, Pradier O. Platelet function in sepsis. Crit Care Med. 2002;30(5 Suppl):S313-7. [PubMed: 12004253].

11. Akca S, Haji-Michael P, de Mendonca A, Suter P, Levi M, Vincent JL. Time course of platelet counts in critically ill patients. Crit Care Med. 2002;30(4):753-6. [PubMed: 11940740].

12. Van der Lelie J, Von dem Borne AK. Increased mean platelet volume in septicaemia. J Clin Pathol. 1983;36(6):693-6. [PubMed: 6343437].

13. Dastugue N, Picheloup F, Sie P, Genestal M, Cathala B, Boneu B. [Increase in mean platelet volume in shock-related thrombocytopenia]. Nouv Presse Med. 1982;11(39):2899-901. [PubMed: 7145676].

14. Aydemir H, Piskin N, Akduman D, Kokturk F, Aktas E. Platelet and mean platelet volume kinetics in adult patients with sepsis. Platelets. 2015;26(4):331-5. doi: 10.3109/09537104.2012.701027. [PubMed: 22731700].

15. Oncel MY, Ozdemir R, Yurttutan S, Canpolat FE, Erdeve O, Oguz SS, et al. Mean platelet volume in neonatal sepsis. J Clin Lab Anal. 2012;26(6):493-6. doi:10.1002/jcla.21552. [PubMed: 23143634].

16. Goldstein B, Giroir B, Randolph A, International Consensus Conference on Pediatric S. International pediatric sepsis consensus conference: definitions for sepsis and organ dysfunction in pediatrics. Pediatr Crit Care Med. 2005;6(1):2-8. doi: 10.1097/01.PCC.0000149131.72248.E6. [PubMed: 15636651].

17. Boechat Tde O, Silveira MF, Faviere W, Macedo GL. Thrombocitopenia in sepsis: an important prognosis factor. Rev Bras Ter Intensiva. 2012;24(1):35-42. [PubMed: 23917711].

18. Zakynthinos SG, Papanikolaou S, Theodoridis T, Zakynthinos EG, Christopoulou-Kokkinou V, Katsaris G, et al. Sepsis severity is the major determinant of circulating thrombopoietin levels in septic patients. Crit Care Med. 2004;32(4):1004-10. [PubMed: 15071393].

19. Kim CH, Kim SJ, Lee MJ, Kwon YE, Kim YL, Park KS, et al. An increase in mean platelet volume from baseline is associated with mortality in patients with severe sepsis or septic shock. PLoS One. 2015;10(3):e0119437. doi: 10.1371/journal.pone.0119437. [PubMed: 25742300].

20. Gao Y, Li Y, Yu X, Guo S, Ji X, Sun T, et al. The impact of various platelet indices as prognostic markers of septic shock. PLoS One. 2014;9(8):e103761. doi: 10.1371/journal.pone.0103761. [PubMed: 25118886]. 
21. Ahmad MS, Waheed A. Platelet counts, MPV and PDW in culture proven and probable neonatal sepsis and association of platelet counts with mortality rate.J Coll Physicians Surg Pak. 2014;24(5):340-4. [PubMed: 24848393].

22. British Committee for Standards in Haematology BTTF. Guidelines for the use of platelet transfusions. Br J Haematol. 2003;122(1):10-23. [PubMed: 12823341].

23. Dellinger RP, Levy MM, Rhodes A, Annane D, Gerlach H, Opal $\mathrm{SM}$, et al. Surviving sepsis campaign: international guidelines for management of severe sepsis and septic shock: 2012. Crit Care Med. 2013;41(2):580-637. doi: 10.1097/CCM.ob013e31827e83af. [PubMed: 23353941].
24. Van der Linden T, Souweine B, Dupic L, Soufir L, Meyer P. Management of thrombocytopenia in the ICU (pregnancy excluded). Ann Intensive Care. 2012;2(1):42. doi: 10.1186/2110-5820-2-42. [PubMed: 22929300].

25. Guida JD, Kunig AM, Leef $\mathrm{KH}$, McKenzie SE, Paul DA. Platelet count and sepsis in very low birth weight neonates: is there an organism-specific response?. Pediatrics. 2003;111(6 Pt 1):1411-5. [PubMed: 12777561].

26. Bhat MA, Bhat JI, Kawoosa MS, Ahmad SM, Ali SW. Organism-specific platelet response and factors affecting survival in thrombocytopenic very low birth weight babies with sepsis. JPerinatol. 2009;29(10):7028. doi: 10.1038/jp.2009.72. [PubMed: 19554015]. 